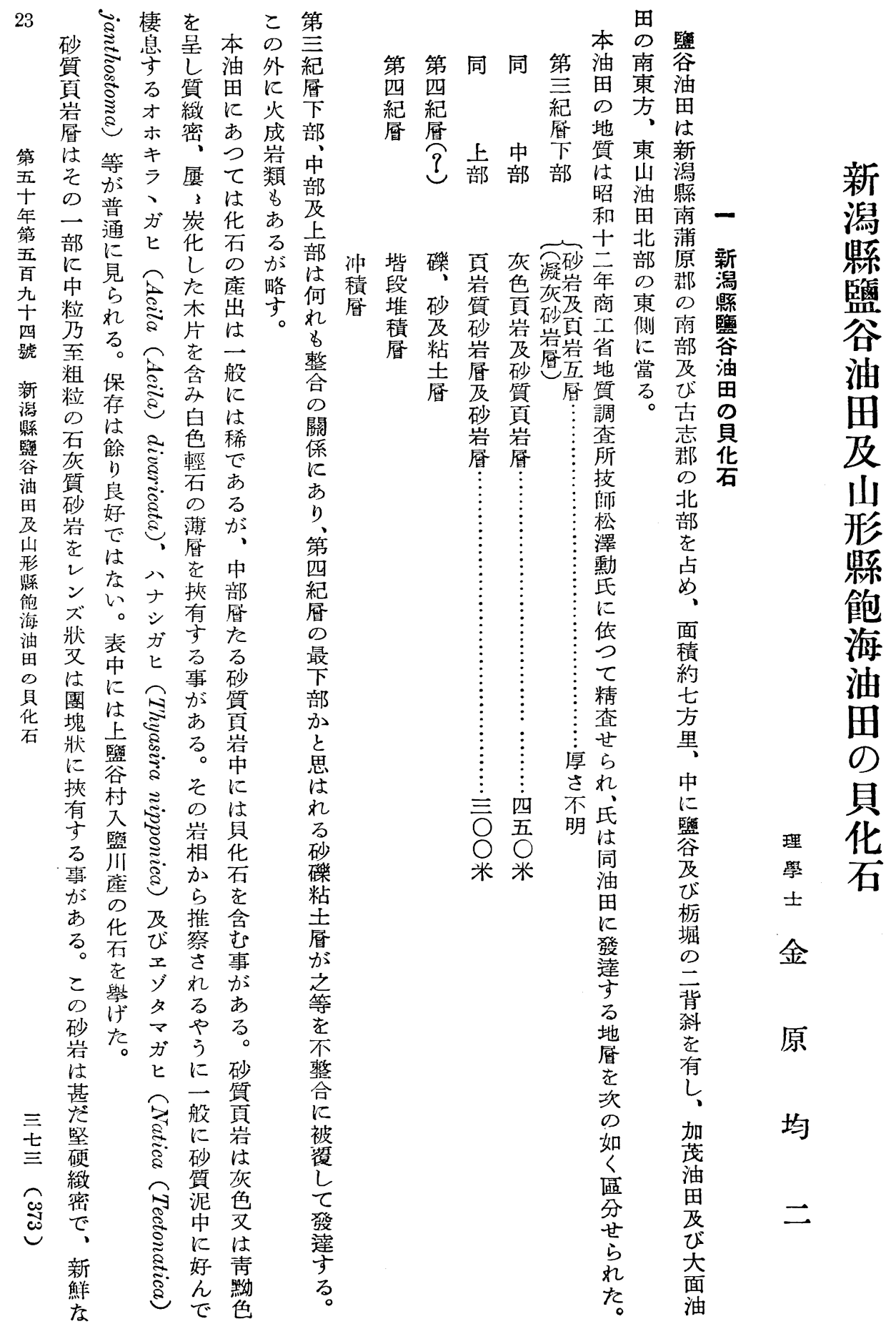




\section{第一表 (Table I)}

1. Acila (Acila) mirabilis (Hinds)

2. Acila (Truncacila) insignis (Gould)

3. Yoldia (Cnesterium) notabilis Yokoyama

4. Glycymeris yessoensis (Sowerby)

5. Anadara trilineata amicula (Yokoyama)

6. Anomia lischkei Dautzenberg et Fischer

7. Pecten (Patinopecten) sp.

8. Venericardia ferruginea (Clessin)

9. Astarte borealis (Schumacher)

10. Lucina acutilineata (Conrad)

11. Taras ustus (Gould)

12. Thyasira nipponica Yabe et Nomura

13. Cardium (Cerastoderma) ciliatum shinjiense Yok.

14. Mercenaria yokoyamai Makiyama

15. Venus (Chione) chitaniana (Yokoyama)

16. Liocyma sp.

17. Macoma aff. nipponica (Tokunaga)

18. Macoma tokyoensis Makiyama

19. Cuspidaria (Cardiomya) gouldiana Hinds

20. Dentalium sp.

21. Umbonium (Suchium) sp.

22. Homalopoma amussitata (Gould)

23. Turritella (Haustator) fortilirata Sowerby

24. Turritella (Haustator) fortilirata saishuensis Yokoyama

25. Natica (Tectonatica) janthostoma Deshayes

26. Trophonopsis (Boreotropnon) xestra (Dall)

27. Japelion pericochlion (Schrenck)

28. Argobuccinum (Priene) oregonensis (Redfield)

29. Oliva mustellina Lamarck

30. Admete lischkei (Yokoyama)

31. Terebra lischkeana Dunker

32. Clavatula cfr. dainichiensis (Yokoyama)

33. Spirotropis (Antiplanes) perversa contraria (Yokoyama)

34. Gcnota (Brachytoma) gracilis (Yokoyama)

35. Lora dissoluta (Yokoyama)

36. Lora candida (Yokoyama)

37. Conus sp.

Moguradani Irishiokawa$$
\text { マ }
$$

ガ 型 部

七中のは

○に㘱淡

出地青

苂見壮灰

₹ 5 上

太ิ

है

がは岩

之弆间

に ン

次

き,

고

y

タ

$\checkmark$

奖

管

(ี

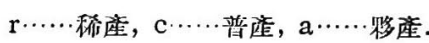

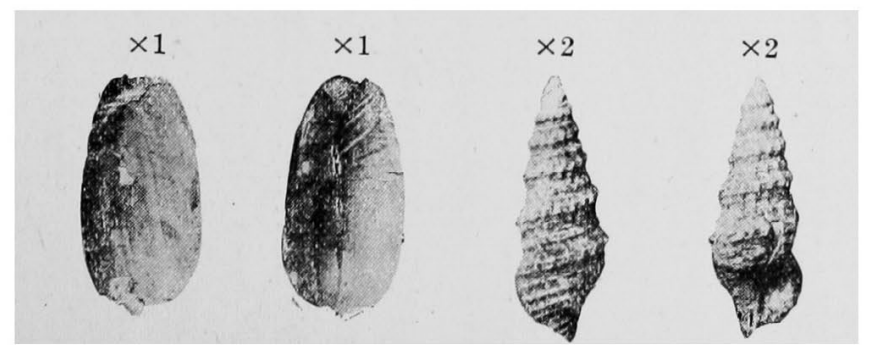

Oliva mustellina Lamarck

Clavatula efr. dainichiensis

(Yokoyama)
分

る 代

?

最全

ちに

個古化

體

數

多

の 砂

24

第

十 
北 飽

り、說去は前は先對愿

村 油

女防少揭方表 世貝こ

の思

に た 所

一 は

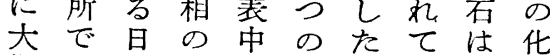

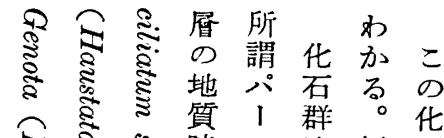

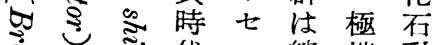

第 部 酒

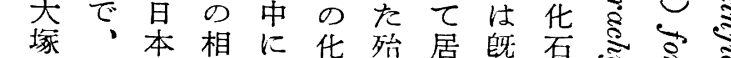

心. 代 ン 總 端 動

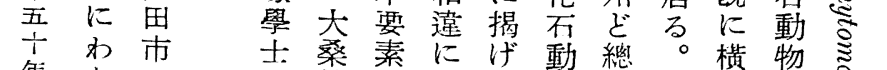

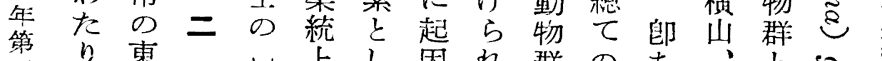

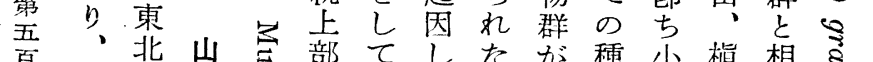$$
\text { 西 }
$$

號 的 在

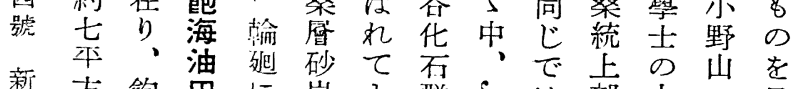

蒩方飽田に岩よ群こは部大の昆

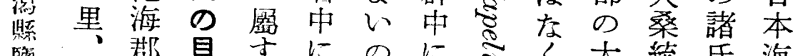

にのに宁統氏海

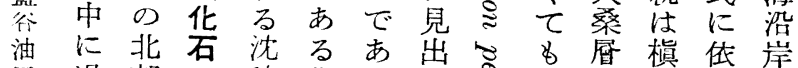

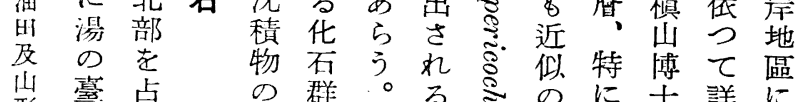

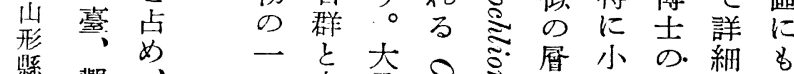

触

海

油

○) 新府

具出杜

石

觀

音同至越緢

寺郡花統 が

옹 屡 小

平旦

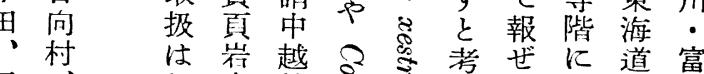

田

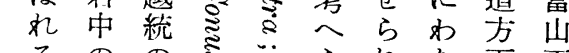

涬大囬 るの

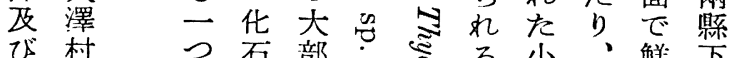

び村つ石部? る゙ 小鮮贸

北、觀 デ

俣觀 デが對は㟔村質統大

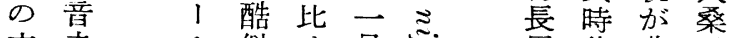

六寺夕似せ見芯屋代典愿

背村 $と$ し $ら$ 黑

斜

抱佰

。村

三 東
至畋
思

村

草

界

考てれ溚る

万る 事、等

れ事は喛が

るは既流長

化注的び

石心゙に佐

群 薢 發 渡

中新薘の

に紀 し 澤

期に悉 屋

せ野と

5 山多採

れ 罺思集

た士はさ

如飞れれ

でるる゙い

及

含 前 乙 根

ま坐居 愿

れ部るが

て遈之

居中江に

る心掛當

云方地 。

事方方桑

胥: 沃 1 種 に 定 ヂ 整潮 は

尽る染十寒見

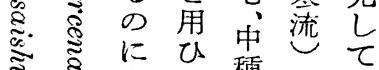

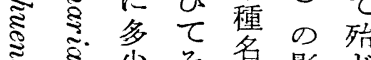

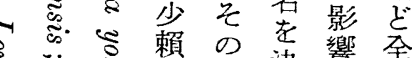

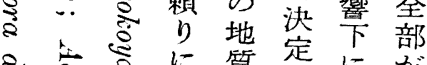

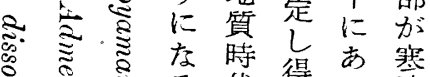

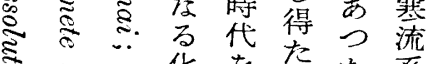

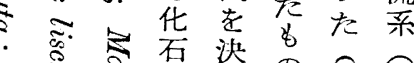

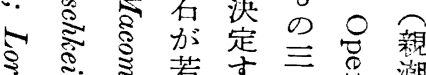

$\therefore$ 若 す文恕潮

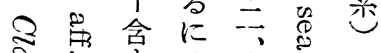

怘怘机餘棲 の

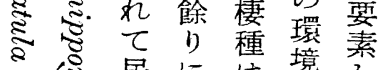

虽怘居に總十竟古

2

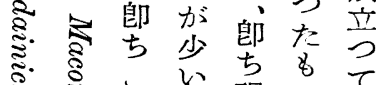

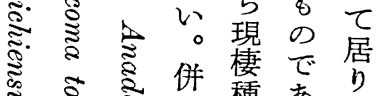

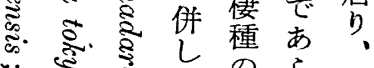

市

心

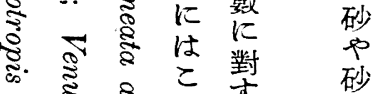

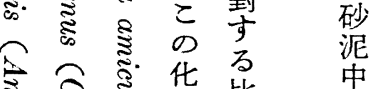

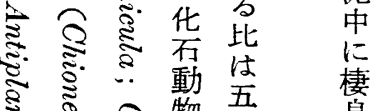

胥尺物五棲

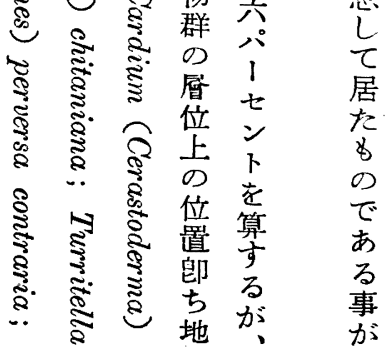




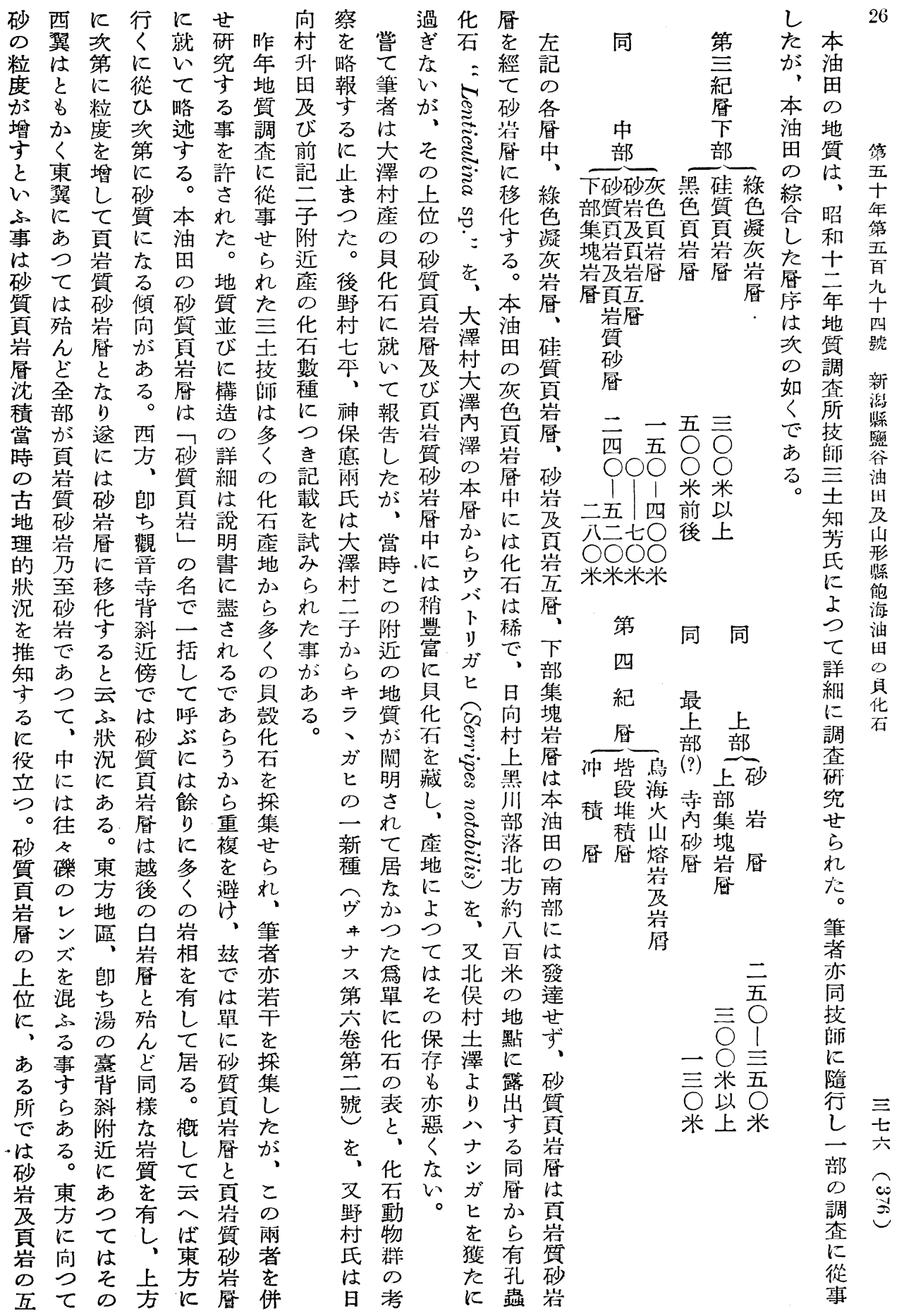




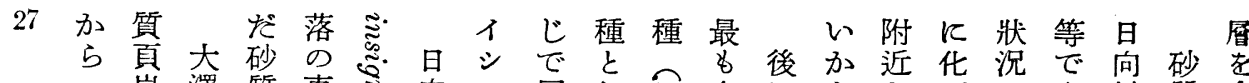

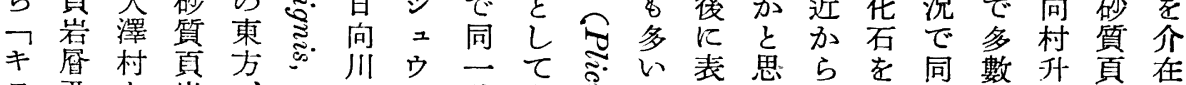

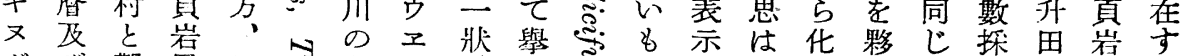

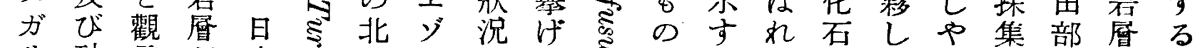

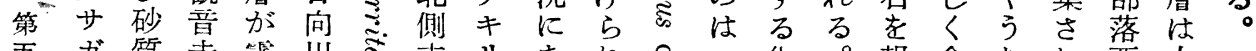

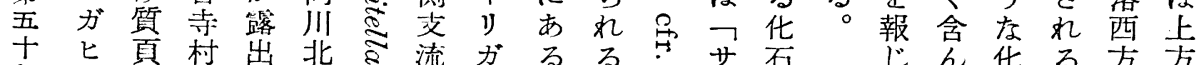

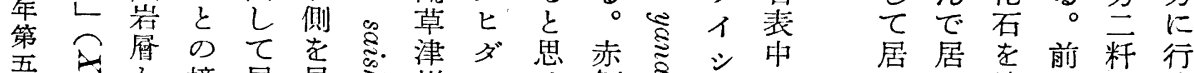

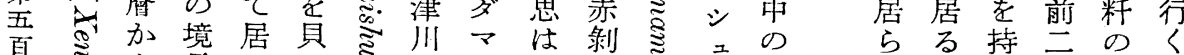

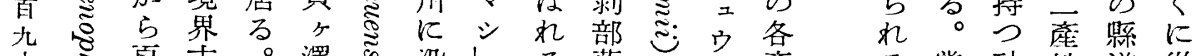

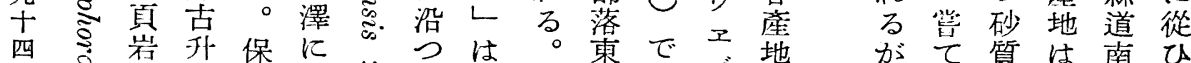

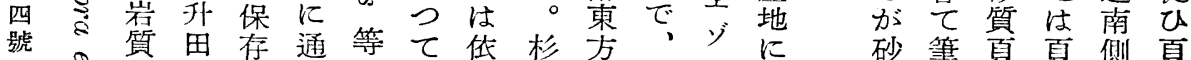

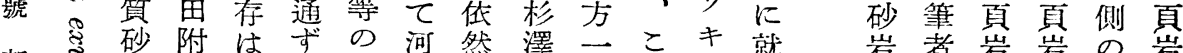
新壳岩近良る凹床存谷籸のリ就岩者岩岩の岩

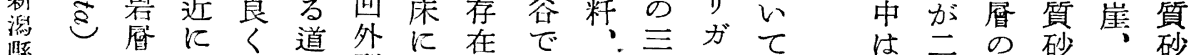

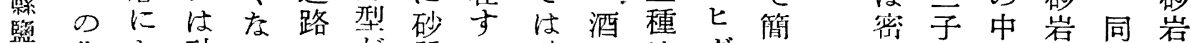
谷化か砂いのが質る砂田はダ單集座に相村愿 油石け質。雨埋頁が質發他マにに

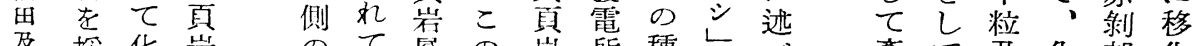

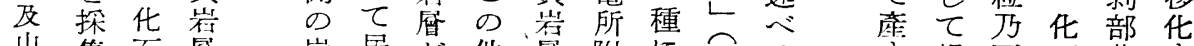

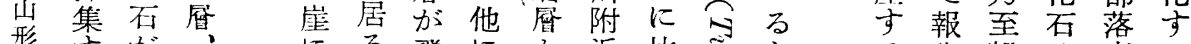

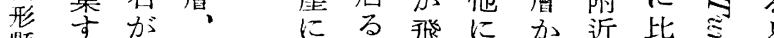

縣る埋頁は事びフ

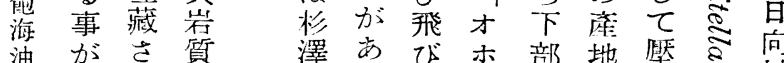

出出机砂谷るにノ集は侄を禁

の來て岩只。籍ガ塊前的㣽. 升

貝た居歷場圣出七岩記に范升

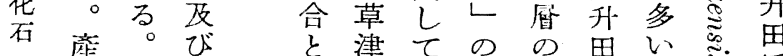

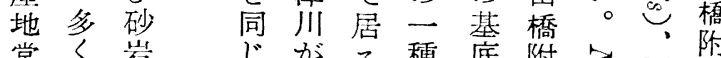

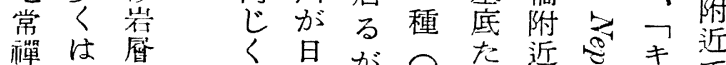

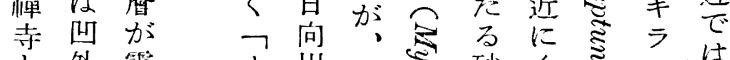

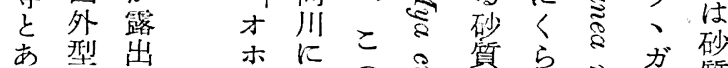

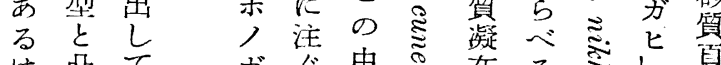
は凸て芯ぐ中怘灰る交し頁

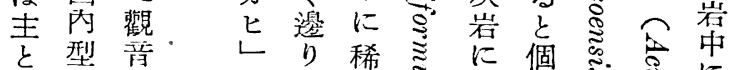

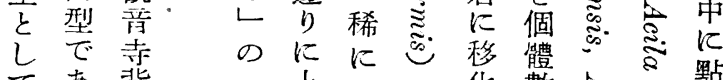
てあ背禾草さが华數き念點

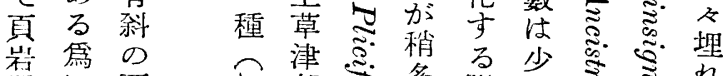

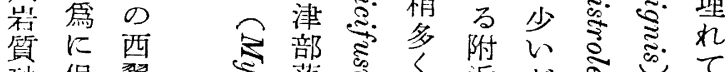
砂 保 翼

三岩存を

七廨は形

七中良成

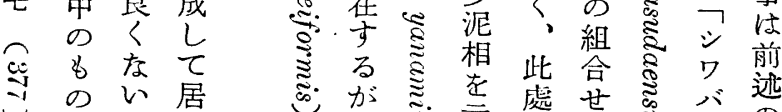

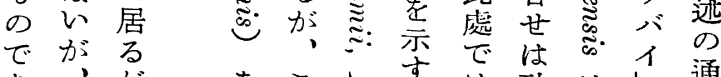
が 化怘及市 る告粗は㝠 る ᄀし 粒 特 方 事 キたの别一は 之化砂に籸前 ヤ石岩は酒述 ゴのが密田し 上大垗集發た 類部ませ電が を分れず所こ 探 はて 概附の 集こあし近潮 さのりて 縣移 れ砂'點道潩 な岩一队南の 分分部飞侧部 つらは埋の分 た探砅当崖に 點集質れ及は かさをてび概 見れ哇居大澤て る る るが村化

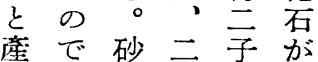
地 あ岩子附多 がつのに近い 少た厚あ流 異野はさて筫华 な村三はのは る學来同北旦

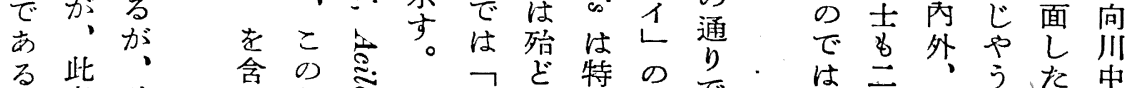

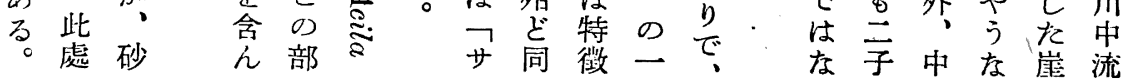




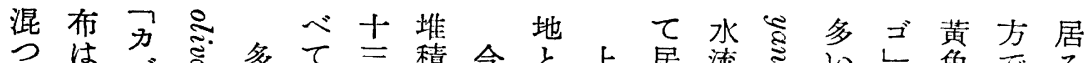

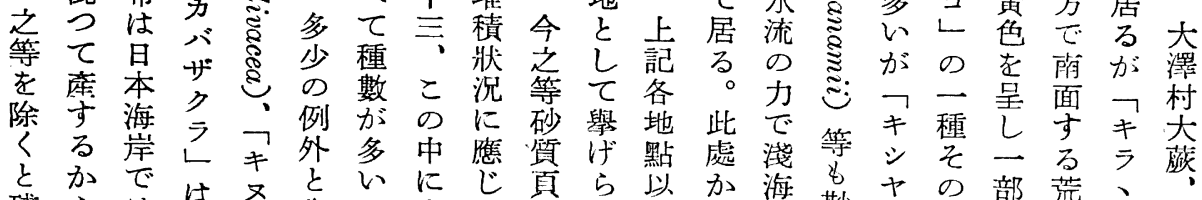

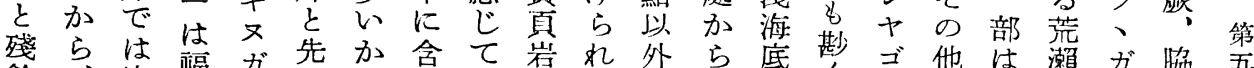

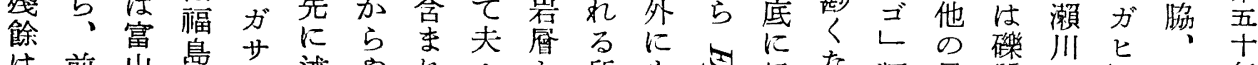

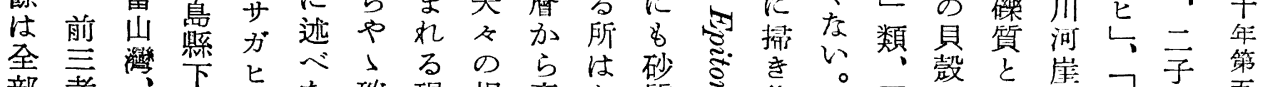

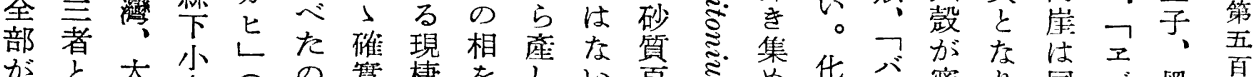

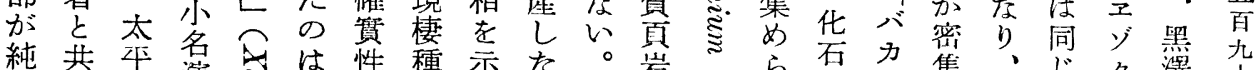

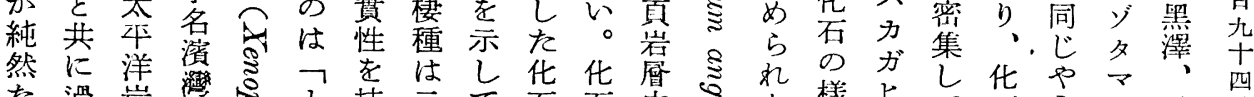

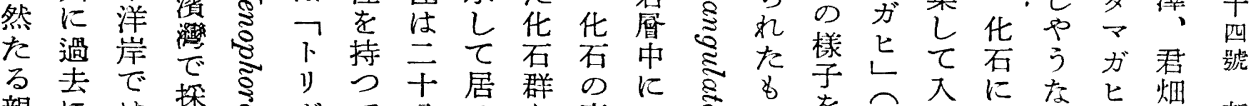

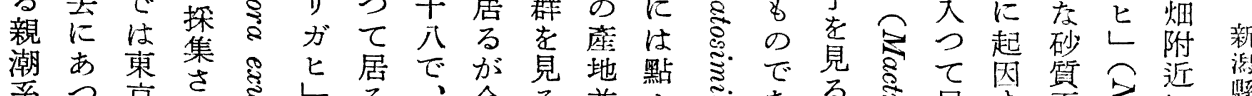

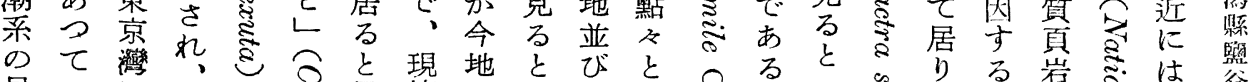

貝のに灣等思棲愿々、゙

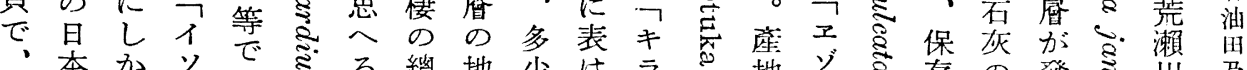

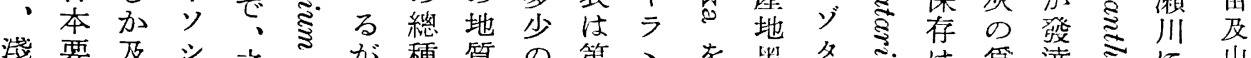

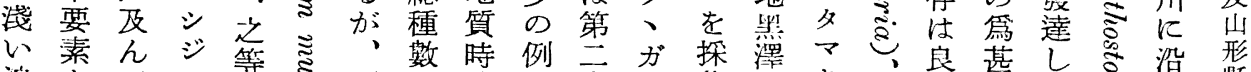

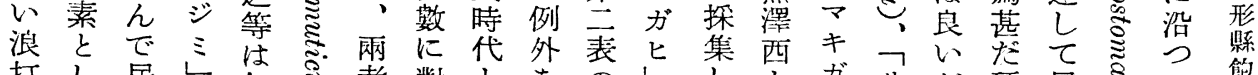

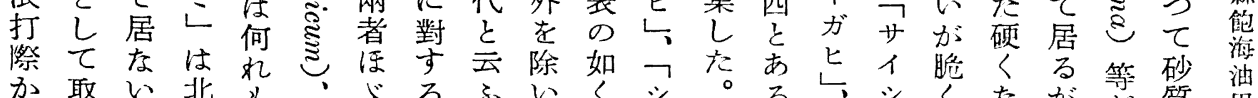

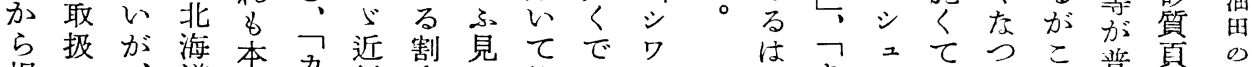

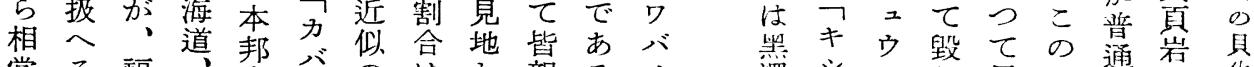

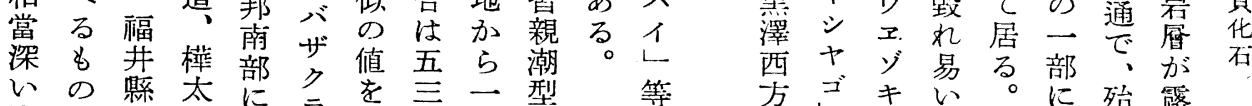

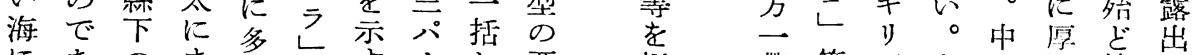

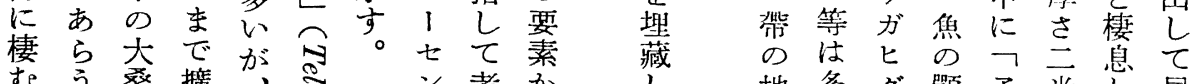

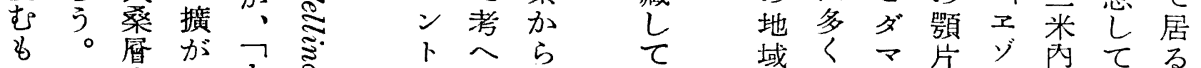

の中虫了る成居或は等夕外居。

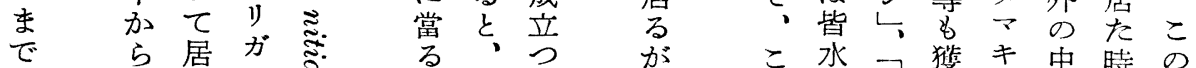

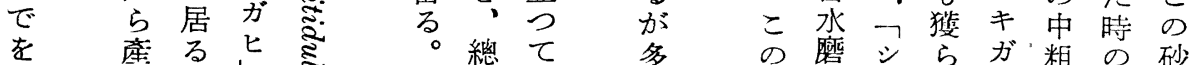

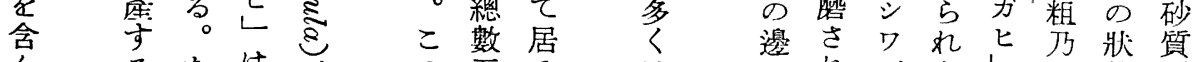

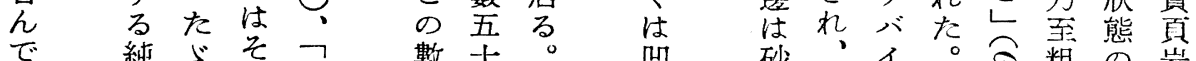

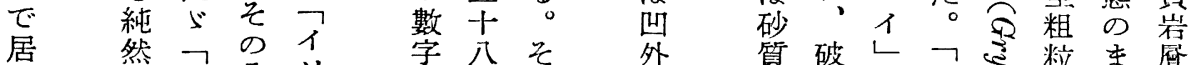

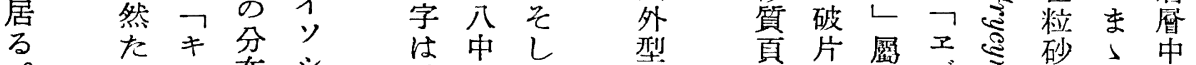

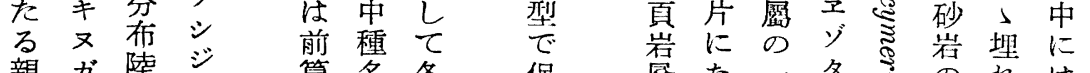

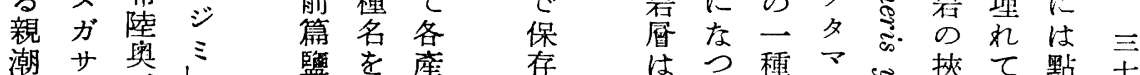

湖 型县ミ

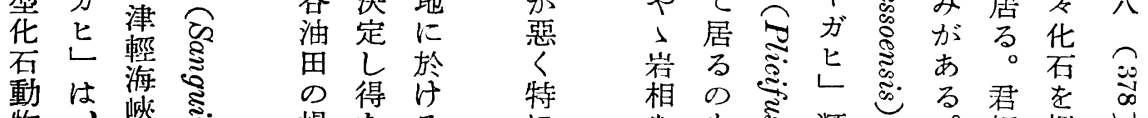

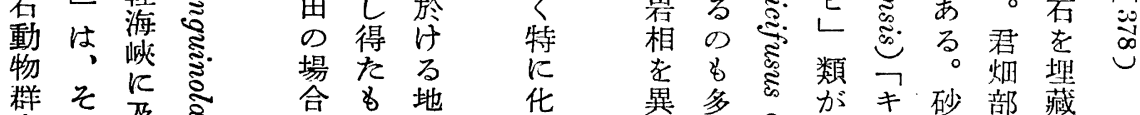

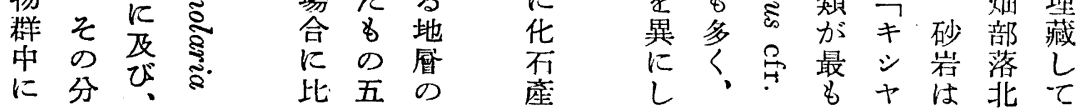




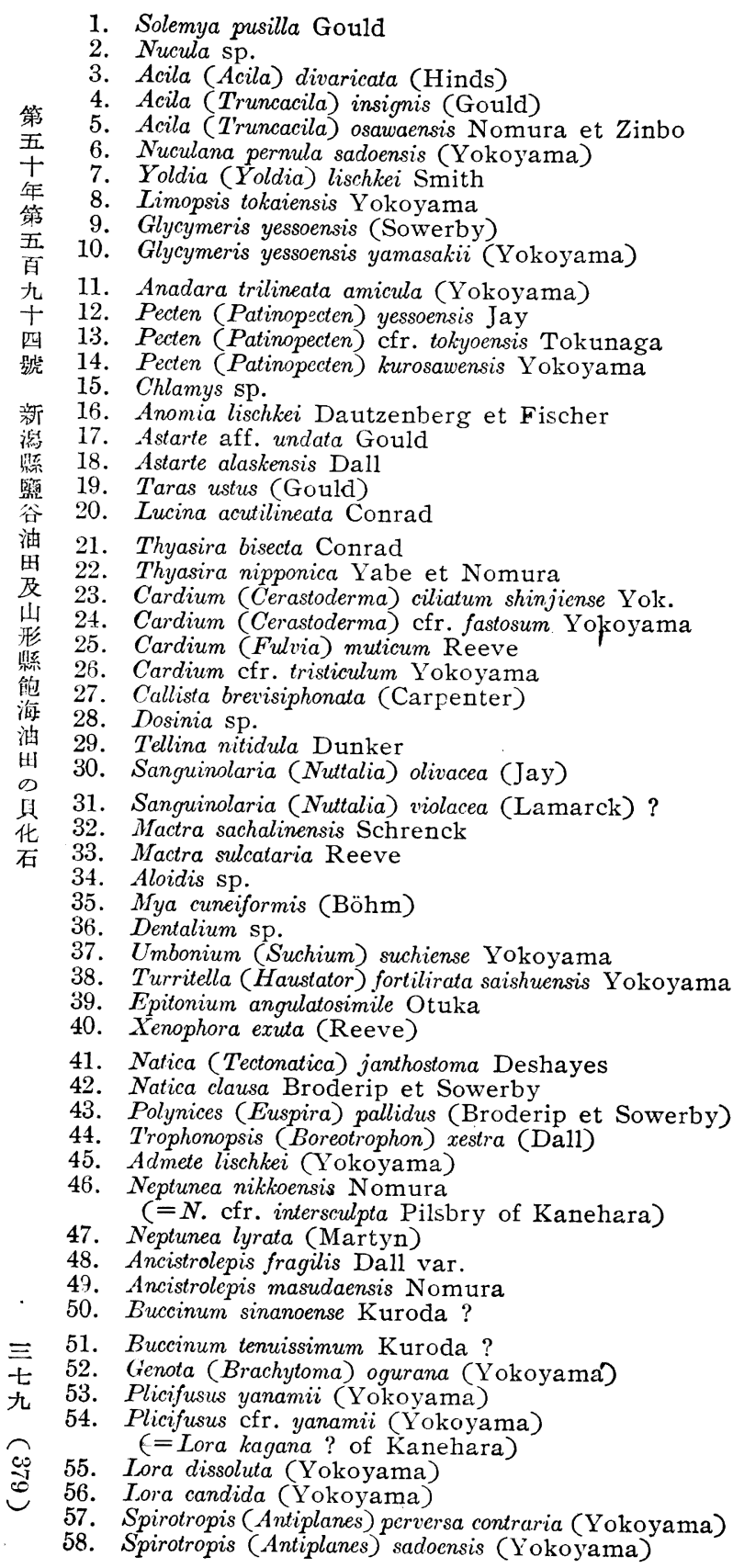

1. Solemya pusilla Gould

2. Nucula sp.

Acila (Acila) divarica

. Acila (Truncacila) insignis (Gould)

6. Nuculana pernula sadoensis (Yokoyama)

Yoldia (Yoldia) lischkei Smith

11. Anadara trilineata amicula (Yokoyama)

12. Pecten (Patinopecten) yessoensis Jay

14. Pecten (Patinopecten) efr. Tokyoensis Tokunaga

15. Chlamys sp.

a

Thyasira bisecta Conrad

23. Cardium (Cerastoderma) ciliatum shinjiense Yols.

24. Cardium (Cerastoderma) cfr. fastosum Yoloyama

27. Callista brevisiphonata (Carpenter)

Dosinia sp.

31. Sanguinolaria (Nuttalia) violacea (Lamarck) ?

Mactra sachalinensis Schrenck

36. Dentalium sp.

Umbonium (Suchium) suchiense Yokoyama

39. Epitonium angulatosimile Otuka

40. Xenophora exuta (Reeve)

1. Natica (Tectonatica) janthostoma Deshayes

Polynices (Euspira) pallich (Broderip

$=N$.

47. Neptunea lyrata (Martyn)

48. Ancistrolepis fragilis Dall var.

49. Ancistrolepis masudaensis Nomura

50. Buccinum sinanoense Kuroda?

51. Buccinum tenuissimum Kuroda

七 52. Genota (Brachytoma) ogurana (Yokoyama)

九 53. Plicifusus yanamii (Yokoyama)

(=Lora kagana? of Kanehara)

Lora dissoluta (Yokoyama)

57. Spirotropis (Antiplanes) perversa contraria (Yokoyama)

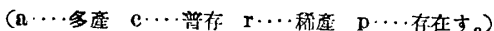

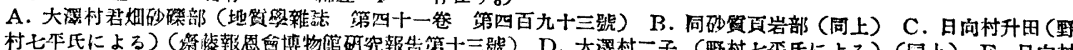

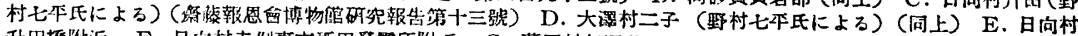

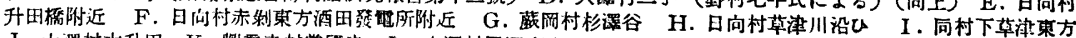

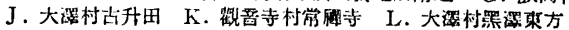

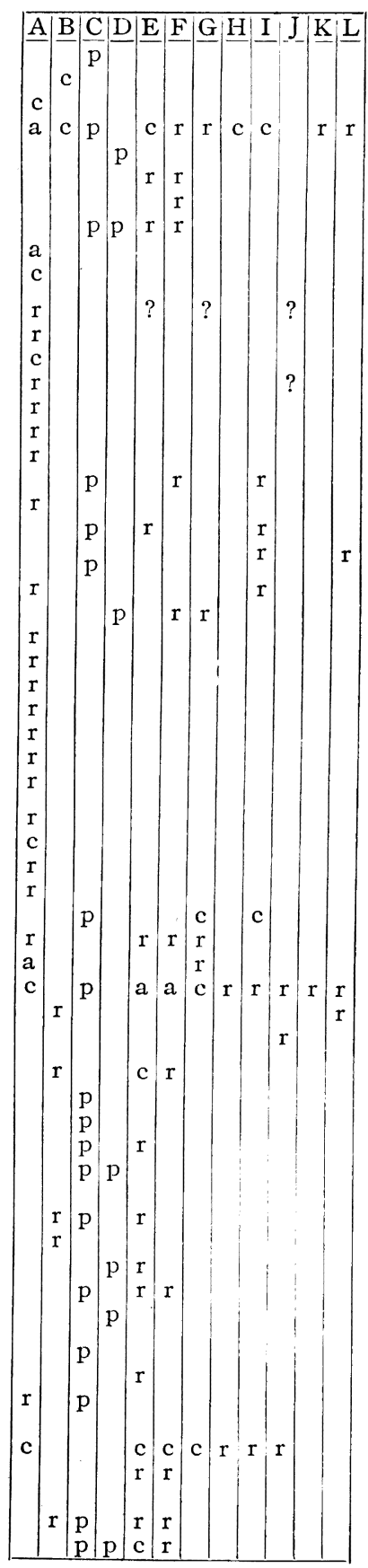




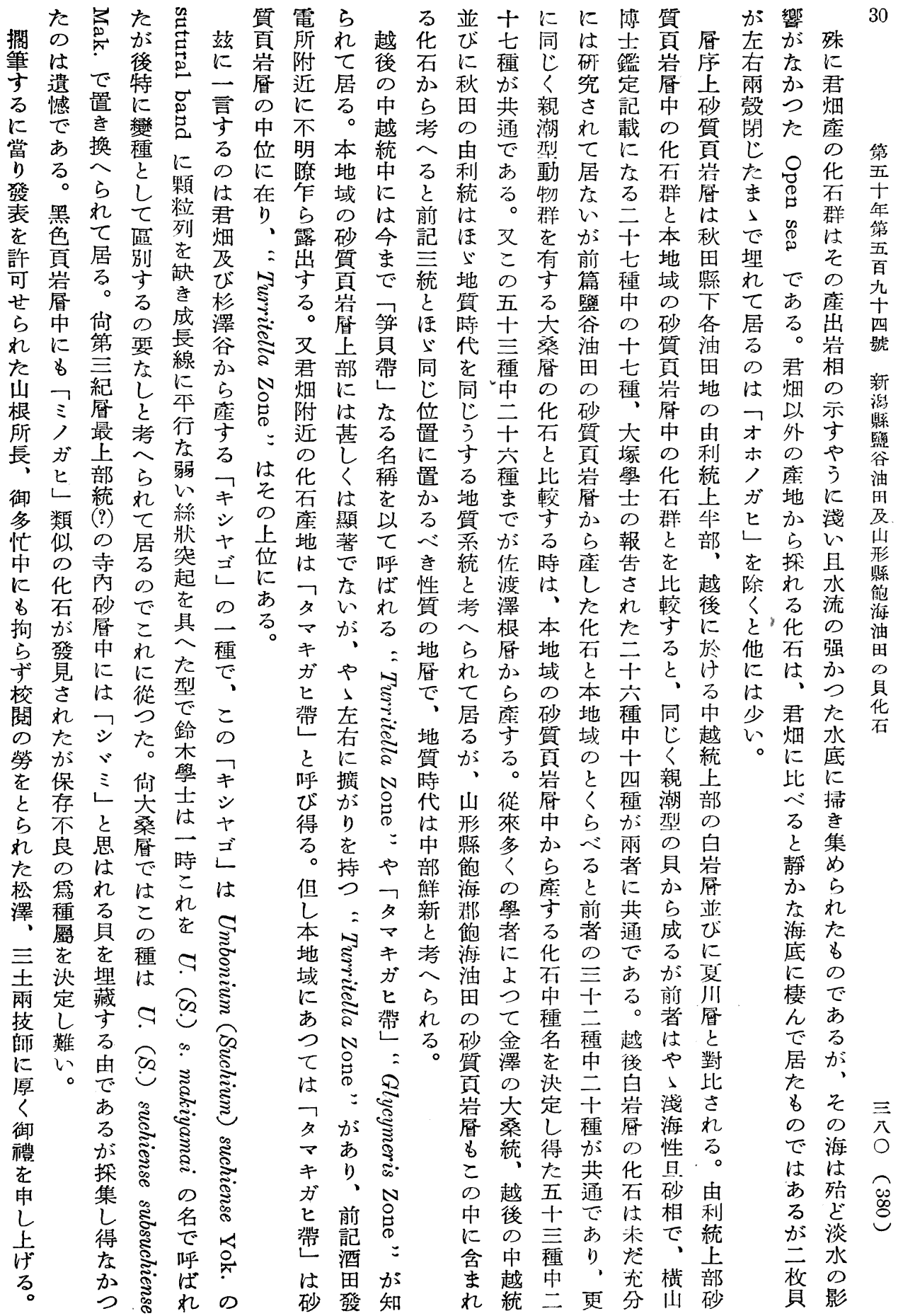




\title{
PLIOCENE SHELLS FROM THE SHIODANI AND AKUMI OIL-FIELDS.
}

\author{
(Abstract)
}

Kinji Kanehara

Part I. Pliocene Shells from the Shiodani Oil-Field, Niigata Prefecture.

The stratigraphy of the Shiodani Oil-Field, Niigata Prefecture, was fully investigated by Mr. I. Matsuzawa of the Imperial Geological Survey of Japan, according to whom the geological sequence of this area, enumerated from below, is as follows:

Tertiary

Lower Series............ $\left\{\begin{array}{l}\text { Alternation of Sandstone and Shale. } \\ \text { (Tuff Sandstone.) }\end{array}\right.$

Middle Series.......... Gray Shale and Sandy Shale. $\quad 450 \mathrm{~m}$.

Upper Series .......... Shaly Sandstone and Sandstone. $300 \mathrm{~m}$.

Uppermost Series $\cdots \cdot . \cdot$ Sand, Gravel and Clay.

Quaternary

Terrace Deposits and Alluvium.

Although fossil shells are rather rare in this field, we find many well preserved shells in the "Sandy Shale", especially in the sand lenses of this horizon. The total faunal list is given in Table I. of the Japanese paper. A glance at the table is sufficient to show that this fauna is a mixed one, that is to say, a fauna of the sand facies is mixed with that of mud. The fauna, no doubt, is of cold current (Oyashio) type.

The species that have been determined number only 32 ; the number of those that are not known to be living now amount to 14 , which is 44 percent of the entire fauna. Needless to say, the number of fossils is too small to allow any determination of the geological age of this fauna. But we find some important fossil species, such as Clavatula cfr. dainichiensis (Yokoyama), Anadara trilineata amicula (Yokoyama), Mercenaria yokoyamai Makiyama, Turritella (Haustator) fortilirata saishuensis Yolioyama, etc.-all essential components of the so-called Omma fauna of Kaga Province, which fauna is considered as a typical Pliocene fauna of the cold current type. Therefore, the fossil fauna of this field may be said to be of Pliocene (lower to middle) age. 